\title{
Lignocellulose pretreatment technologies affect the level of enzymatic cellulose oxidation by LPMO
}

Rodríguez-Zúñiga, Ursula Fabiola; Cannella, David; de Campos Giordano, Roberto; de Lima Camargo Giordano, Raquel; Jørgensen, Henning; Felby, Claus

\author{
Published in: \\ Green Chemistry \\ Link to article, DOI: \\ 10.1039/C4GC02179G \\ Publication date: \\ 2015 \\ Document Version \\ Peer reviewed version \\ Link back to DTU Orbit
}

Citation (APA):

Rodríguez-Zúñiga, U. F., Cannella, D., de Campos Giordano, R., de Lima Camargo Giordano, R., Jørgensen, H., \& Felby, C. (2015). Lignocellulose pretreatment technologies affect the level of enzymatic cellulose oxidation by LPMO. Green Chemistry, 16, 2896-2903. https://doi.org/10.1039/C4GC02179G

\section{General rights}

Copyright and moral rights for the publications made accessible in the public portal are retained by the authors and/or other copyright owners and it is a condition of accessing publications that users recognise and abide by the legal requirements associated with these rights.

- Users may download and print one copy of any publication from the public portal for the purpose of private study or research.

- You may not further distribute the material or use it for any profit-making activity or commercial gain

- You may freely distribute the URL identifying the publication in the public portal 

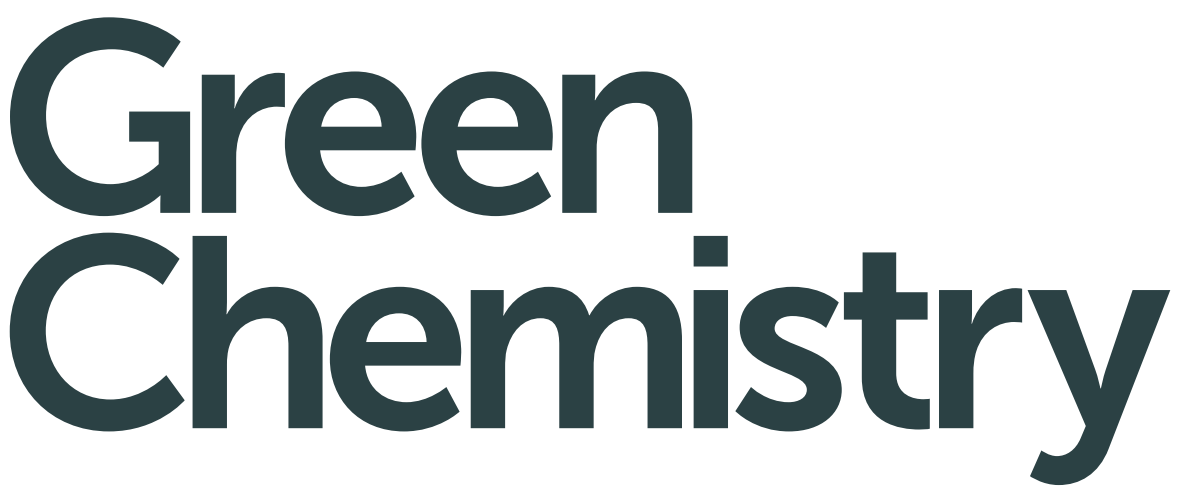

\section{Accepted Manuscript}

This article can be cited before page numbers have been issued, to do this please use: U. F. RodriguezZuniga, D. Cannella, R. D. C. Giordano, R. D. L. C. Giordano, H. Jørgensen and C. Felby, Green Chem.,

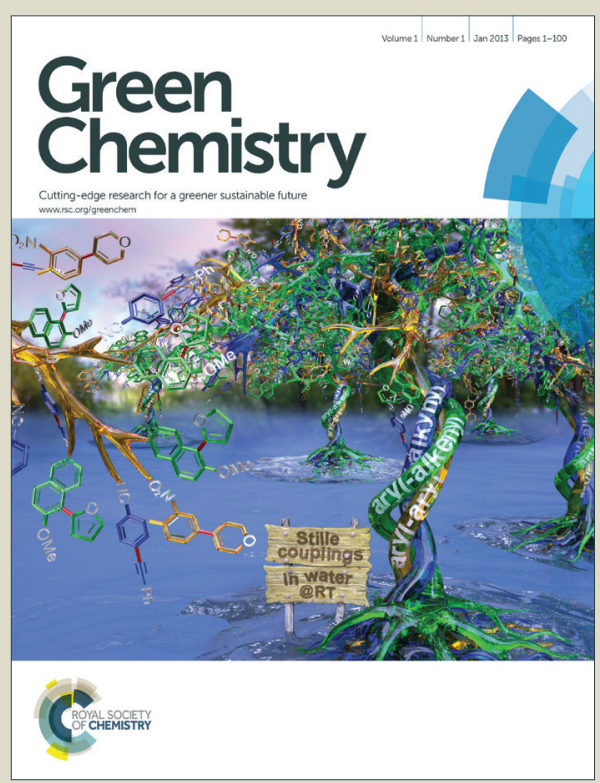

This is an Accepted Manuscript, which has been through the Royal Society of Chemistry peer review process and has been accepted for publication.

Accepted Manuscripts are published online shortly after acceptance, before technical editing, formatting and proof reading. Using this free service, authors can make their results available to the community, in citable form, before we publish the edited article. We will replace this Accepted Manuscript with the edited and formatted Advance Article as soon as it is available.

You can find more information about Accepted Manuscripts in the Information for Authors.

Please note that technical editing may introduce minor changes to the text and/or graphics, which may alter content. The journal's standard Terms \& Conditions and the Ethical guidelines still apply. In no event shall the Royal Society of Chemistry be held responsible for any errors or omissions in this Accepted Manuscript or any consequences arising from the use of any information it contains. 


\title{
1 Lignocellulose pretreatment technologies affect the level of 2 enzymatic cellulose oxidation by LPMO
}

3

4 Ursula Fabiola Rodríguez-Zúñiga ${ }^{1,2^{*}}$, David Cannella ${ }^{1 *}$, Roberto de Campos Giordano ${ }^{2}$,

5 Raquel de Lima Camargo Giordano ${ }^{2}$, Henning Jørgensen ${ }^{1,3}$, Claus Felby ${ }^{1}$

6

$7 \quad$ *These authors contributed equally to the work

8

$9{ }^{1}$ Department of Geosciences and Nature Resource Management, University of Copenhagen, 10 Rolighedsvej 23, DK-1958 Frederiksberg C, Denmark

$11{ }^{2}$ Department of Chemical Engineering, Federal University of São Carlos, Rod. Washington

12 Luís km 235, CEP 13565-905, C.P. 676, São Carlos, SP, Brazil

$13{ }^{3}$ Present address: Center for Bioprocess Engineering, Department of Chemical and Biochemical

14 Engineering, Technical University of Denmark, Building 229, DK-2800 Kgs. Lyngby, Denmark

\begin{abstract}
Sugarcane bagasse, corn stover, and wheat straw are among the most available resources for production of cellulosic ethanol. For these biomasses we study the influence of pre-treatment methods on the chemical composition, as well as on the subsequent reactions of enzymatic hydrolysis and oxidation of cellulose. The applied pre-treatment methods are organosolv, hydrothermal, and alkaline. Hydrothermally pretreated wheat straw gave the highest cellulose conversion with $80 \%$ glucose yield and $0.8 \%$ oxidized cellulose products. Recent studies have shown that lignin is able to boost the activity of the cellulose oxidizing enzyme lytic polysaccharide monooxygenase (LPMO). The highest activity of LPMO was observed for the hydrothermally pretreated biomasses, which also contained the highest level of lignin. All hydrolysis were done at high dry matter levels, using a commercial enzyme preparation containing hydrolytic and oxidative enzymes.
\end{abstract}

28

\section{INTRODUCTION}

30 Agricultural residues such as sugarcane bagasse, corn stover, and wheat straw are the most available sources 31 of lignocellulosic biomass in South America, North America, and Europe, and are therefore the materials of 32 highest interest for cellulosic ethanol production. ${ }^{1}$ 
33 The basic process for cellulosic ethanol is a biochemical conversion of plant biomass by the use of enzymes

34 (cellulases, hemicellulases, and accessory enzymes) to degrade the structural polysaccharides into monomeric

35 sugars, the so-called sugar platform for further microbial transformation into the desired final products.;

36 Prior to the enzymatic conversion, the cellulose chains arranged in highly ordered and tightly packed regions

37 of microfibrils, ${ }^{4}$ needs to be loosened in the cell wall matrix in order to make the crystalline structure more

38 accessible to cellulose-degrading enzymes. ${ }^{5}$ Therefore the first step that the biomass undergo is a physico-

39 chemical pretreatment, ${ }^{6}$ which alters the chemical and physical structure of the hemicellulose and lignin

40 matrix, providing a more accessible cellulose component. Numerous pre-treatment strategies have been

41 developed over the past decades, showing that no single universal method can be successfully applied to all

42 types of biomass, reflecting the wide range of biomass structures and inherent recalcitrance. ${ }^{6 ; 7}$

43 In search of industrially relevant scenarios for the enzymatic breakdown of cellulose, a common approach is 44 to operate the process at high dry matter (DM). ${ }^{8: 9}$ Such conditions are advantageous from a techno-economic 45 perspective, ${ }^{10}$ but working at high DM e.g. above $20 \%$, can be problematic due to impaired performance of 46 the cellulolytic enzymes. A new generation of commercial cellulolytic cocktails offers several improvements 47 compared to earlier products, one of the most important is a greater tolerance to high DM conditions by the 48 use of improved $\beta$-glucosidases. ${ }^{11}$ Another development is the introduction of a new class of cellulose 49 oxidizing enzymes, known as lytic polysaccharide monooxygenases (LPMOs), classified today as AA9, 50 AA10, and AA11. 9;12;13

51 Conventional mechanistic models of the cellulolytic machinery composed of exo- and endo-cellulases does not include the action of the LPMO enzymes. ${ }^{14}$ The LPMOs will oxidatively cleave the cellulose chains and act synergistically with the hydrolytic enzymes. ${ }^{15}$ The product is oxicelluloses with a normal non-reducing end and a C1-oxidized end, or native reducing end and an oxidation of the $\mathrm{C} 4$ at the non-reducing terminal. 16:17 The products of the subsequent action of exo-cellulases and $\beta$-glucosidases are the monomeric forms of the carbohydrates, including the oxidized forms of glucose: gluconic acid and gemdiol 4-ketoaldose, $\mathrm{C} 1$ and C4 oxidation, respectively. ${ }^{18}$ This was shown by the seminal studies of Vaje-Kolstad et al., Harris at al. and Beeson et al 2011. ${ }^{12 ; 1719}$ Nowadays the interest within the scientific community is focused towards the structure and functional mechanism of LPMOs, mostly to elucidate how the electrons are transferred via LPMO during the redox action. ${ }^{15}$

61 It has also been shown that pivotal is the role of cofactors for the redox activity: LPMO is boosted by adding 62 electron donors such as ascorbic acid, gallic acid, and reduced glutathione, which are not found in plant cell 63 walls. ${ }^{19 ; 20}$ Moreover also enzymes can donate electrons and this is the case of CDH. ${ }^{15}$ Since LPMOs have 64 been found to oxidize lignocellulosic substrates without the addition of an external electron donor, lignin has 65 been speculated to be the electron supplier for the activity of LPMOs. ${ }^{19 ; 21 ; 22}$ Moreover, to the best of our 66 knowledge, few studies ${ }^{9 ; 22}$ have focused on the action of these enzymes in the complex system of a real 67 lignocellulosic substrate and within current commercial cellulase cocktails, under industrially relevant 68 conditions. The role of lignin acting as electron donor for LPMOs, used together with cellulase/LPMO 
69 formulations, is thus especially relevant in relation to those pretreatment technologies that target lignin

70 degradation and solubilization (organosolv and alkali pretreatments).

71 Organosolv pretreatment separates cellulose and lignin by extraction of the lignin from lignocellulosic

72 feedstock using an organic solvent. ${ }^{24}$ In this work, ethanol was employed as a solvent, due to its relatively

73 low cost and proven capacity for delignification and hemicellulose solubilization. ${ }^{25 ; 26}$

74 Soda treatment is a classical alkaline pulping process that is mainly used industrially to digest wood pulps. Its

75 advantages are the high levels of cellulose remaining, short processing times, and the absence of formation of

76 sulfur by-products. ${ }^{27}$

77 Another option is the acidic hydrothermal pretreatment frequently used for agricultural residues. ${ }^{28}$ It

78 selectively removes the hemicellulose fraction, increasing the overall digestibility of the residual cellulose. In

79 this case most of the LCC-bonds (lignin-carbohydrates complex) are cleaved and the phenolic structures in

80 lignin are reorganized but not removed. ${ }^{29}$

81 This aim of the present work was to obtain a better understanding of the relationship between the lignin 82 remaining in the biomass after pretreatment and the oxidative reactions of LPMO enzymes. Different 83 pretreatment methods (organosolv, hydrothermal, and alkaline) were applied to sugarcane bagasse in order to 84 obtain a residual fraction with different levels and quality of lignin. Hydrothermal pretreatment was then used 85 for three different types of biomass (corn stover, sugarcane bagasse, and wheat straw) in order to determine 86 whether different sources of lignin affected the LPMO catalyzed oxidation of cellulose.

\section{MATERIALS AND METHODS}

\section{$89 \quad 2.1 \quad$ Biomasses}

90 Sugarcane bagasse was kindly donated by the Center for Sugarcane Technology (CTC, Piracicaba, São Paulo, 91 Brazil). Instead Danish wheat straw (Triticum aestivum L.) and corn stover (Zea mays L.) were from an 92 internal collection at University of Copenhagen (Denmark). All the biomasses were dried until $\sim 10 \%$ moisture 93 content, milled to a particle size of $<1 \mathrm{~mm}$ using a Wiley mill, and stored at $-5{ }^{\circ} \mathrm{C}$ during the study. An 94 overnight extraction with hot water was performed in order to remove non-structural material from the 95 biomasses.

$96 \quad 2.2 \quad$ Enzymes

97 Cellic $^{\circledR}$ CTec2 was kindly donated by Novozymes A/S (Bagsvaerd, Denmark). The protein content of the 98 enzymatic preparation was $141.6 \mathrm{mg}$ protein $/ \mathrm{g}$, as determined by the bicinchoninic acid (BCA) assay, 99 performed according to the instructions of the supplier (Pierce, Rockford, IL). The cellulase activity was 100 measured by the filter paper assay giving a value of $126 \mathrm{FPU} / \mathrm{g}$ of preparation. Cellic ${ }^{\circledR} \mathrm{CTec} 2$ was stored at 4 $101{ }^{\circ} \mathrm{C}$ until needed for hydrolysis of the pretreated biomasses. 
103 Two different sets of pretreatment were carried out. The first evaluated the effect of different pretreatment 104 techniques (alkaline, hydrothermal, and organosolv) on the same biomass (sugarcane bagasse) at 10\% DM.

105 The second instead was designed to test the effects the hydrothermal technique on three different biomasses

106 (sugarcane bagasse, wheat straw, and corn stover) at high dry matter contents (20\% DM).

107 In the hydrothermal pretreatment, 10 grams of each biomass were placed separately in $250 \mathrm{~mL}$ blue cap 108 bottles. Distilled water was added to adjust the solids content to $20 \%$ DM. The bottle was placed in a closed 109 metal cylinder and immersed in a high temperature silicone oil bath. The heat-up time was 35-45 min, and the 110 temperature was recorded by a probe in the metal cylinder. After $10 \mathrm{~min}$ at $190^{\circ} \mathrm{C}$, the metal cylinder was 111 removed from the oil bath and cooled in air. All samples were washed with distilled water under vacuum 112 filtration until around $\mathrm{pH} 5$, and stored in a fridge (at $5{ }^{\circ} \mathrm{C}$ ) prior to enzymatic hydrolysis.

113 The alkaline pretreatment was performed in an autoclave for $30 \mathrm{~min}$ at $121^{\circ} \mathrm{C}$. The loading of $\mathrm{NaOH}$ was $4 \%$ $114 \mathrm{w} / \mathrm{w}$ (based on dry bagasse) and the total dry matter loading was $10 \%$.

115 For the ethanol organosolv treatment, $25 \mathrm{~g}$ (dry basis) of sugarcane bagasse was mixed with aqueous ethanol $116(50 \%)$ to give a final DM loading of $10 \%$. The mixture was treated in a $5.0 \mathrm{~L}$ Parr pressure reactor equipped 117 with temperature controller (Parr Instrument Company, Moline, IL). The reaction mixture was heated at 190 $118{ }^{\circ} \mathrm{C}$ for $90 \mathrm{~min}$, with continuous stirring.

119 All the pretreated materials were extensively washed with distilled water to eliminate the soluble molecules 120 generated during the pretreatments. In the case of the organosolv pretreatment, the pulp was first washed with 121 ethanol solution at $50 \%(\mathrm{v} / \mathrm{v})$ and then with hot water $\left(60^{\circ} \mathrm{C}\right)$.

$122 \quad 2.4 \quad$ Hydrolysis

123 Hydrolysis of the pretreated biomasses $(75 \mathrm{mg}$, dry basis) was performed in $2 \mathrm{~mL}$ Eppendorf tubes, with 124 mixing in a tumbler reactor system for $96 \mathrm{~h}$ at $48{ }^{\circ} \mathrm{C}$ and an enzyme loading of $10 \mathrm{FPU} / \mathrm{g}$ glucan. The water 125 content was adjusted with a buffer solution of $50 \mathrm{mM}$ sodium acetate to obtain a final loading of $15 \% \mathrm{DM}$. 126 Samples were removed from the reactor at 24 hours intervals and boiled for $10 \mathrm{~min}$. at $105{ }^{\circ} \mathrm{C}$ to stop the 127 enzymatic reaction. The supernatant was separated by centrifugation for further analysis of glucan conversion 128 and quantification of oxidized products.

$129 \quad 2.5 \quad$ Biomass compositional analysis and sugar analysis

130 The total solids, structural carbohydrate, and lignin contents of the raw and pretreated biomasses were 131 analyzed using standard laboratory analytical procedures (LAP) developed by the National Renewable Energy 132 Laboratory (NREL). ${ }^{30}$ For the structural carbohydrate determination, sugar analysis was performed with a 133 Dionex ICS5000 HPAEC system (Dionex, Sunnyvale, CA, USA) equipped with a pulsed amperometric 134 detector (PAD), a CarboPac-PA1 2x250 mm analytical column, and a CarboPac PA1 2x50 mm guard column. 135 The columns were maintained at $30{ }^{\circ} \mathrm{C}$. Pure water was used as the main eluent for $32 \mathrm{~min}$ at $0.250 \mathrm{~mL} / \mathrm{min}$, 
136 followed by a washing step with $0.25 \mathrm{M} \mathrm{NaOH}$ for $10 \mathrm{~min}$, after which the initial conditions were restored for

$13715 \mathrm{~min}$, prior to a new injection. For the post-column eluent, a solution of $0.2 \mathrm{M} \mathrm{NaOH}$ was added at 0.1

$138 \mathrm{~mL} / \mathrm{min}$ during each step.

139 The ash content of the solid fraction was determined by incineration of $0.5 \mathrm{~g}$ of dried sample at $550{ }^{\circ} \mathrm{C}$ for $3 \mathrm{~h}$.

140 The glucose released in the enzymatic hydrolysis experiments was measured using an UltiMate 3000 HPLC

141 (Dionex, Germering, Germany) equipped with a refractive index detector (Shodex, Japan). The separation was

142 performed with a Phenomenex Rezex ROA column, kept at $80{ }^{\circ} \mathrm{C}$, with $5 \mathrm{mM} \mathrm{H}_{2} \mathrm{SO}_{4}$ as eluent at a flow rate

143 of $0.6 \mathrm{~mL} / \mathrm{min}$. The results were analyzed using Chromeleon software (Dionex).

$144 \quad 2.6$ Analysis of oxidized products

145 HPAEC was conducted using an ICS5000 system (Dionex, Sunnivale, CA, USA) equipped with a gold 146 electrode PAD. Samples (2, 5, or $10 \mu \mathrm{L}$ in $50 \mathrm{mM} \mathrm{NaOH})$ were injected onto a column system comprising a 147 CarboPac PA1 2x250 mm analytical column (Dionex, Sunnivale, CA, USA) and a CarboPac PAC1 2x50 mm 148 guard column, maintained at $30{ }^{\circ} \mathrm{C}$. The gradient elution method used has been described in detail 149 previously. ${ }^{18}$

$150 \quad 2.7$ FT-IR Spectroscopy

151 The resulting lignocellulosic materials after the pretreatments were analyzed by a Thermo Nicolet 6700 FT-IR 152 spectrometer equipped with a Golden Gate (diamond) ATR accessory and DTGS (KBr) detector. For the 153 analysis of lignin fractions the crystal temperature of the detector was set at $25^{\circ} \mathrm{C}$. A background of 150 scans 154 was acquired, and the spectrum of each sample is reported as the average of three spectra. The maximum 155 absorbance peak at $1025 \mathrm{~cm}^{-1}$ typically associated with cellulose, was chosen for normalization such that $156 A\left(1025 \mathrm{~cm}^{-1}\right)=1$.

\section{RESULTS AND DISCUSSION}

160 The pretreatment methods and biomasses utilized are shown in the experimental plan (Figure 1), in which the two main series of experiments are highlighted. In the first, different pretreatments (organosolv, hydrothermal, 162 and alkali) were applied to sugarcane bagasse. In the second set of experiments, the hydrothermal 163 pretreatment was applied to the different biomasses (corn stover, sugarcane bagasse, and wheat straw). The 164 two series of pretreatments were conducted with different dry matter (DM) contents: 10\% and 20\%, 165 respectively. The structural carbohydrates (cellulose and hemicellulose), lignin, and ash contents were 166 measured before and after the pretreatments (Tables 1 and 2). All the pretreated biomasses were hydrolyzed 167 with the Cellic Ctec2 cellulolytic cocktail containing a LPMO enzyme. 


\section{$170 \quad$ 3.1.1 Different pretreatments of sugarcane bagasse}

171 Sugarcane bagasse was pretreated using the organosolv, hydrothermal, and alkaline techniques. All the 172 pretreatments where carried out at 10\% (w/w) DM loading, and the chemical composition of the solid fraction

173 was determined before and after the pretreatments (Table 1). As expected, each pretreatment had a different

174 effect in terms of the main structural components of the biomass, but overall the greatest changes occurred for 175 xylan and lignin. Total xylan was reduced by $87 \%$ after the hydrothermal pretreatment, while reductions of $17626 \%$ and $46 \%$ were obtained for the organosolv and alkaline pretreatments, respectively. After the organosolv 177 and alkali pretreatments, the cellulose content increased by more than $60 \%$, compared to the raw material, 178 while an increase of only $5 \%$ was obtained for the hydrothermal pretreatment (Table 1, and Figure 2: 179 qualitative data from FT-IR spectra region $900-1200 \mathrm{~cm}^{-1}$ ).

180 Lignin was affected differently by the pretreatment methods applied. An overview of the pretreatment effects 181 is given by the FT-IR spectra which were collected for all the pretreated materials and compared with the raw 182 sugarcane bagasse spectra (Figure 2). Mainly the peak at $1510 \mathrm{~cm}$ was analyzed as indicative for lignin and a 183 correlation with the chemical composition analysis has been found: organosolv and alkaline pretreatment 184 spectra stands out with a limited (if not) absorbance, whereas hydrothermal pretreatment spectra gained 185 absorbance when compared to the raw material. In overall the last two spectra has a coherent overlap, whereas 186 the organosolv and alkali induced such radical changes that the spectra are not comparable to the raw material, 187 qualitatively and semi-quantitatively. Organosolv pretreatment, using an aqueous/organic solvent mixture at $188 \mathrm{pH} 3.6$, removed $61 \%$ of the lignin, due to cleavage of hemicellulose-lignin bonds or the hydrolysis of 189 glycosidic bonds in hemicelluloses releasing hemicellulose-lignin fragments, and the cleavage of $\alpha$-aryl and $\beta$ 190 aryl ethers in the native lignin. ${ }^{31}$ Alkaline treatment provided the greatest lignin removal of $70 \%$. The alkaline 191 process also cleaves the $\alpha$-ether and ester linkages in the phenolic polymer and between lignin and 192 polysaccharides. In general, both organosolv and alkaline delignification act on the $\beta$-O-4' alkyl-aryl ether 193 linkages, which are the most common intra-molecular linkages in the lignin. A complete delignification is 194 harder to achieve, because of the carbon-carbon linkages in the residual lignin.

195 The effect of the hydrothermal treatment on lignin did not achieve any quantitative removal. Lignin was not 196 reduced in the residual substrate, although it has been found that spatial reorganization can occur, with 197 droplets appearing on the surface of the fibers. ${ }^{29}$ These droplets are the result of 198 depolymerization/repolymerization after the transition of lignin from a glassy state to a rubbery state, followed 199 by coalescence and migration from the cell wall. ${ }^{28 ; 32}$

200 3.1.2 Hydrolysis of sugarcane bagasse pretreated using organosolv, hydrothermal, and alkali methods

201 The solid fractions of pretreated sugarcane bagasse were enzymatically hydrolyzed for $96 \mathrm{~h}$, at $15 \% \mathrm{DM}$ 202 loading. The glucan and xylan conversion profiles are shown in Figure 3. The highest cellulose conversions 203 were observed for the hydrothermal and alkaline pretreatments, despite their different levels of residual lignin 
204 (38 and 8\% w/w, respectively). Hence, the presence of lignin did not appear to have any important impact on 205 the hydrolytic action of the enzyme. The recalcitrance of the pretreated bagasse therefore appeared to be 206 associated with the amount of residual hemicellulose, which was higher for the organosolv pretreated bagasse, 207 with a consequently lower hydrolysis efficiency of $60 \%$ glucan conversion, as well as physical characteristics 208 of the cellulose. Besides the overall larger removal of lignin, the alkaline pretreated substrates also showed 209 high cellulose digestibility, with a conversion yield of $94 \%$. Structural effects that have been reported after 210 soda processes include swelling of the remaining cellulose fibers, together with decreased crystallinity and 211 lower degree of polymerization. ${ }^{33 ; 34}$ In the case of the hydrothermally pretreated bagasse, hydrolysis of the 212 cellulose fraction reached $87 \%$.

213 Improved xylan hydrolysis has been achieved by the inclusion of accessory enzymes such as endo-xylanases 214 and xyloglucanase in the latest commercial enzyme cocktails, contributing to the conversion of the 215 hemicellulose fraction. The xylan conversion trends observed here were generally similar to the corresponding 216 glucan conversions for each pretreatment method (Figures 3a and 3b). Interestingly, the relative hydrolysis of 217 xylan around $65 \%$ was similar for the bagasse samples pretreated by the hydrothermal and alkaline methods. 218 However, the absolute amount of xylan converted was higher for the alkaline pretreated bagasse, which 219 contained four times more hemicellulose, compared to the hydrothermally pretreated material.

220 The role of lignin as a physical barrier to cellulolytic enzymes during hydrolysis has been much discussed. ${ }^{35}$ 221 The organosolv pretreatment reduced the lignin fraction of the bagasse to a small percentage $(\sim 10 \%)$ of the 222 remaining solids fraction, while the glucan hydrolysis yield was only $60 \%$. In contrast, despite a greater 223 quantity of residual lignin, use of the hydrothermal pretreatment method resulted in $87 \%$ glucan conversion. A 224 question therefore arises concerning the role of lignin as a barrier to enzymatic hydrolysis, and the possibility 225 that specific chemical compositions or structural architectures of lignin might affect the enzymes or the 226 recalcitrance of the lignocellulose. The selection of pretreatment technique might be an important factor 227 affecting the lignin pool, due to the occurrence of different chemical or structural modifications. For example, 228 organosolv treatment leads to the phenomenon of covalent repolymerization of lignin derivatives on the 229 cellulose fiber surface, hence restricting access of the cellulases. Lignin deconstruction and repolymerization 230 reactions involving the formation of new carbohydrate-phenolic complexes (by means of $\beta-\beta, \beta-1$, and $\beta-5$ 231 linkages) have been reported. ${ }^{31}$ The residual hemicellulose and repolymerized lignin evident in organosolv 232 pretreated biomasses might function as a barrier and reduce the cellulase activity, hence explaining the lower 233 enzymatic conversion. ${ }^{36}$

234 Hydrothermal pretreatment results in lignin relocation in the form of droplets physically adsorbed to the 235 cellulose surface. Since these clustered lignin structures are adsorbed, they might be displaced from the 236 cellulose surface by the progressive action of exo-cellulases (cellobiohydrolases), as proposed by Li et al., ${ }^{37}$ so 237 that only partial restriction of enzymatic activity would occur. Moreover, together with an almost complete 238 removal of xylan, very high overall cellulose hydrolysis values $(\sim 95 \%)$ have been reported for wheat straw 239 that was hydrothermally pretreated at a DM content of $30 \%{ }^{9}$ 


\subsubsection{Effect of pretreatment technique on LPMOs activity}

241 The activity of LPMOs during the hydrolysis of bagasse was monitored in order to identify the influence of

242 the type of pretreatment technique applied. The concentration of gluconic acid was used as a marker of

243 cellulose oxidation occurring at the $\mathrm{C} 1$ position of the pyranose rings constituting the cellulose fibers. It has

244 been already demonstrated that this oxidative activity can be attributed to the LPMOs contained in the Cellic

245 Ctec2 cellulolytic cocktail used in this work. ${ }^{21}$ The results are reported as the level of cellulose oxidation,

246 calculated as the percentage of hydrolyzed cellulose, measuring the concentration of gluconic acid relative to

247 the concentration of glucose, at each time point (Figures 3 and 5). Using this procedure, only the hydrolysable

248 cellulose is measured, rather than the total available cellulose, which is preferable because LPMOs only act on

249 the surface of the cellulose substrate. It is important to note that the enzymatic hydrolysis was carried out

250 without addition of any external electron donor, such as the ascorbic acid used in previous studies. ${ }^{12 ; 38}$ The

251 intention was to determine whether lignin may act as a native electron donor for LPMOs, and whether the type

252 of pretreatment technique affected this characteristic of the lignin applied.

253 The highest gluconic acid concentration after $96 \mathrm{~h}$ of hydrolysis was obtained using hydrothermally pretreated 254 bagasse, with $0.43 \%$ cellulose oxidation and hydrolysis of $87 \%$ of the cellulose. The organosolv pretreated 255 bagasse showed only $0.12 \%$ cellulose oxidation, and there were no detectable oxidized products for the 256 bagasse submitted to alkaline pretreatment (the analytical sensitivity of the instrument was $5 \mathrm{ppm}$ ). These 257 results correlate with the different quantities of lignin remaining after the pretreatment processes, being the 258 hydrothermal having the highest amount.

259 If in one hand the amount of remaining lignin seems to be the mandating factor for a highest level of cellulose 260 oxidation, in the other the physicochemical properties of the remaining lignin could also differ, and thus to be 261 considered for further speculations. Similar concentrations of lignin were found in the materials submitted to 262 alkaline and organosolv pretreatments, but their capacities to act as electron donors for the LPMOs were not 263 the same. Previous work has shown that lower depolymerization of lignin is induced by organic solvents, 264 compared to alkaline depolymerization. ${ }^{39}$ It is possible that the phenolic fractions in the organosolv pulps 265 might have higher molecular weight and greater thermal stability than those released by the alkaline process, 266 and these characteristics could affect a possible electron donor capacity. According to Trajano et al., ${ }^{28}$ lignin 267 can be dissolved in hot liquid water environments, but its high reactivity causes the fast recondensation of the 268 moieties, which reprecipitate on the pretreated fibers. Using optical techniques, Coletta et al. ${ }^{32}$ observed that 269 under acid conditions, that solubilized lignin molecules react with monomers and oligomers to form larger 270 molecules. The native lignin structure can therefore be affected by these processes and undergo changes in its 271 stable or metastable conformation at the nanoscale. ${ }^{32 ; 37}$

272 It has been reported that the deconstruction of the lignocellulose matrix by LPMOs follows a redox 273 mechanism, with participation of the synergistic action of the fungal cellulases. A new synergy will result 274 after the oxidative disruption of the crystalline cellulose chain, where the pyranose ring undergoes 
275 transformation after the introduction of a charged carboxylic end, in the case of $\mathrm{C} 1$ oxidation. ${ }^{15}$ The

276 disruption of the crystalline packing due to LPMOs will therefore increase the accessibility of the substrate to

277 hydrolytic cellulases, and this synergy is enhanced by the presence of an electron donor. The results indicate

278 the capability of pretreated lignin to act as a reducing agent by supplying the electrons needed for the

279 oxidation step, confirming earlier findings by $\mathrm{Hu}$ et al. ${ }^{21 ; 22 ; 23}$

\section{3.2. Enhancement of LPMOs activity using hydrothermal pretreatment}

\section{3.2.1 Hydrothermal pretreatment of different biomasses}

282 Three biomasses (sugarcane bagasse, wheat straw, and corn stover) were selected to study the effect of 283 different compositions and structures of the lignocellulose when hydrolyzed with cocktail containing LPMOs.

284 Hydrothermal pretreatment was chosen because the resulting lignin was more reactive for the redox activity of 285 the LPMOs. Table 2 shows the compositions of the biomasses before and after the hydrothermal treatment 286 carried out at $190{ }^{\circ} \mathrm{C}$ for 10 minutes, using $20 \%(\mathrm{w} / \mathrm{w}) \mathrm{DM}$ content.

287 At elevated temperatures and pressures $\left(180-230^{\circ} \mathrm{C}\right.$ and 2.4-2.8 MPa) liquid water behaves like an acid, and 288 the $\mathrm{pH}$ values of water at 190 and $220^{\circ} \mathrm{C}$ are around 5.8 and 5.5, respectively. ${ }^{33}$ Acetic acid, produced from 289 deacetylation of the hemicellulose, also enhances the acid-catalyzed reactions. As a result, hemicellulose is 290 hydrolyzed to soluble oligomers and monomers, and glucans are affected because the liquid fraction contains 291 a certain amount of monomeric glucose. Lignin and glucans presented different ratios in the residual solids 292 fraction of the pretreated biomasses, with wheat straw being more enriched in cellulose ( 20\%), compared to 293 corn stover $(\sim 10 \%)$ and sugarcane bagasse $(\sim 8 \%)$. Due to the solubilization of the hemicellulose, there was an 294 increase in the relative level of Klason lignin of about $50 \%$ for all the pretreated biomasses.

\section{3.2.2 Hydrolysis of hydrothermally pretreated biomasses}

296 Different to the earlier experiments (section 3.1.1), the pretreatments here were conducted using $20 \%$ DM 297 loadings, and 15\% DM loading was maintained for the subsequent enzymatic hydrolyses. Wheat straw 298 lignocellulose showed the highest digestibility, with production of $80 \%$ of the maximum theoretical glucose 299 yield. The overall hydrolysis yield for corn stover, where both glucan and xylan were converted at 50\% of 300 their maximum yields, was slightly lower than reported elsewhere for corn stover. ${ }^{34}$ The yield for bagasse 301 decreased when the pretreatment was done at a higher level of solids (Figure 4). The chemical compositions 302 of bagasse hydrothermally pretreated using DM loadings of $10 \%$ and $20 \%$ were similar, but the latter yielded $30320 \%$ lower conversion after $96 \mathrm{~h}$ of enzymatic hydrolysis. This indicates that despite similar contents of 304 cellulose and lignin (Table 2), the structural and morphological characteristics of the two materials were 305 different.

306 Figure 5 shows the LPMOs activity, calculated as the amount of gluconic acid produced relative to the 307 production of glucose during the enzymatic hydrolysis. The table included in Figure 5 summarizes the global 308 production of gluconic acid at the end of the hydrolysis, compared with the lignin content. All the 
309 hydrothermally pretreated biomasses led to higher amounts of oxidized cellulose, indicative of higher LPMO

310 activity, as compared to the organosolv and alkaline methods. It could therefore be inferred that there were no

311 substantial differences between the lignins of the three different biomasses used in this work, in relation to

312 their capacity to react with the LPMOs. It is notable that the amount of gluconic acid detected increased in

313 line with the solids loading used in the pretreatment (from $10 \%$ to $20 \%$ of DM for the hydrothermal

314 pretreatment of sugarcane bagasse). This was even more evident when the relative oxidation as a percentage

315 of the glucose released was taken into account. The lower release of glucose for the bagasse pretreated at $20 \%$

316 DM resulted in cellulose oxidation values approximately $50 \%$ higher than for the bagasse pretreated at $10 \%$

317 DM.

\section{CONCLUSIONS}

320 The results obtained in this study are significant in terms of selection of the pretreatment method applied to 321 lignocellulosic biomass prior to enzymatic hydrolysis in biorefineries, with the aim of maximizing the 322 oxidative activity of the LPMO enzymes. The production of gluconic acid was monitored during the 323 enzymatic hydrolysis, as a marker for $\mathrm{C} 1$ oxidation of the glucose monomers composing the cellulose fibers, 324 resulting from LPMO catalysis. The residual lignin present in the solid fraction of the pretreated biomass 325 influenced the oxidative activity of the LPMOs, and hydrothermal pretreatment was identified as resulting in 326 better preservation of the reactivity of the lignin, compared to organosolv and alkaline techniques. The benefit 327 of hydrothermal pretreatment was observed for all the agricultural residues studied (corn stover, sugarcane 328 bagasse, and wheat straw), showing that the origin of the lignin did not affect its capacity to potentially act as 329 an electron donor for LPMOs. 
1 D. Bacovsky, N. Ludwiczek, M. Ognissanto, M. Wörgetter, IEA Bioenergy Task 39, 2013.

2 S. Dutta, K. C. W. Wu, Green Chem., 2014, 16, 4615-4626.

3 A. J. Ragauskas, C. K. Williams, B. H. Davison, G. Britovsek, J. Cairney, C. A. Eckert, W. J. Frederick, J. P. Hallet, D. J. Leak, C. L. Liotta, J. R. Mielenz, R. Murphy, R. Templer, T. Tschaplinski, Science, 2006, 311, 484-489.

4 P. Sarkar, E. Bosneaga, M. Auer, J. Exp. Bot., 2013, 60, 3615-3635.

5 V. Arantes, J. N. Saddler, Biotechnol. Biofuels, 2011, 4, 3.

6 M. Galbe, G. Zacchi, Adv Biochem. Eng. Biotechnol., 2007, 108, 41-65.

7 R. Chandra, R. Bura, W. Mabee, A. Berlin, X. Pan, J. Saddler, Adv. Biochem. Eng.

Biotechnol., 2007, 108, 67-93.

8 H. Jørgensen, J. B. Kristensen, C. Felby, Biofuels Bioproducts \& Biorefining-Biofpr 2007, 1, 119-134.

9 D. Cannella, H. Jørgensen, Biotechnol. Bioeng. 2014, 111, 59-68.

10 S. Macrelli, J. Mogensen, G. Zacchi, Biotechnol. Biofuels, 2012, 5, 22.

11 C. C. Hsieh, D. Cannella, H. Jørgensen, C. Felby, Lisbeth G.Thygesen, J. Agric. Food Chem.,2014, 62, 3800-3805.

12 G. Vaaje-Kolstad, B. Westereng, S. J. Horn, Z. L. Liu, H. Zhai, M. Sorlie, V. G. H. Eijsink, Science 2010, 330, 219-222.

13 A. Levasseur, E. Drula, V. Lombard, P. Coutinho, B. Henrissat, Biotechnol. Biofuels, 2013, 6, 41 .

14 B. Henrissat, H. Driguez, C. Viet, M. Schulein, Nat. Biotechnol., 1985, 3, 722-726.

15 S. Horn, G. Vaaje-Kolstad, B. Westereng, V. G. Eijsink, Biotechnol. Biofuels, 2012, 5, 45.

16 R. J. Quinlan, M. D. Sweeney, L. Lo Leggio, H. Otten, J. C. Poulsen, K. S. Johansen, K. B. R. M. Krogh, C. I. Jorgensen, M. Tovborg, A. Anthonsen, T. Tryfona, C. P. Walter, P. Dupree, F. Xu, G. J. Davies, P. H. Walton, Proc. Natl. Acad. Sci. USA, 2011, 108, 1507915084.

17 W. T. Beeson, C. M. Phillips, J. H. D. Cate, M. A. Marletta, J. Am. Chem. Soc., 2012, 134, 890-892.

18 B. Westereng, J. W. Agger, S. J. Horn, G. Vaaje-Kolstad, F. L. Aachmann, Y. H. Stenstrøm, 381 V. G. H. Eijsink, J. Chromatogr. A, 2013, 1271, 144-152. 
19 P. V. Harris, D. Welner, K. C. McFarland, E. Re, J. C. Poulsen, K. Brown, R. Salbo, H. Ding, E. Vlasenko, S. Merino, F. Xu, J. Cherry, S. Larsen, L. Lo-Leggio, Biochemistry, 2010, 49, 3305-3316.

20 B. Westereng, T. Ishida, G. Vaaje-Kolstad, M. Wu, V. G. H. Eijsink, 382 K. Igarashi, M. Samejima, J. Stahlberg, S. J. Horn, M. Sandgren, PLoS ONE, 2011, 6, e27807.

21 D. Cannella, C. C. Hsieh, C. Felby, H. Jorgensen, Biotechnol. Biofuels, 2012, 5, 26.

22 M. Dimarogona, E. Topakas, L. Olsson, P. Christakopoulos, Biores. Technol., 2012, 110, 480-487.

23 J. Hu, V. Arantes, A. Pribowo, K. Gourlay, J. N. Saddler, Energy Environ. Sci., 2014, 7, 2308-2315.

24 C. Cateto, G. Hu, A. J. Ragauskas, Energy Environ. Sci., 2011, 4, 1516-1521.

25 M. J. de la Torre, A. Moral, M. D. Hern+índez, E. Cabeza, A. Tijero, Ind. Crops Prod., 2013, 45, 58-63.

26 P. Obama, G. Ricochon, L. Muniglia, N. Brosse, Biores. Technol., 2012, 112,156-163.

27 A. von Schenck, N. Berglin, J. Uusitalo, App. Energy, 2013, 102, 229-240.

28 H. Trajano, N. Engle, M. Foston, A. J. Ragauskas, T. Tschaplinski, C. Wyman, Biotechnol. Biofuels, 2013, 6, 110.

29 J. B. Kristensen, L. G. Thygesen, C. Felby, H. Jørgensen, T. Elder, Biotechnol. Biofuels, 2008, $1,5$.

30 A. Sluiter, B. Hames, R. Ruiz, C. Scarlata, J. Sluiter, D. Templeton, and D. Crocker, Technical Report NREL/TP-510-42618, National Renewable Energy Laboratory, 2011.

31 X. Zhao, K. Cheng, D. Liu, Appl. Microbiol. Biotechnol., 2009, 82, 815-827.

32 V. C. Coletta, C. A. Rezende, F. R. da Conceicao, I. Polikarpov, F. E. G. Guimaraes, Biotechnol. Biofuels, 2013, 6, 43.

33 N. Mosier, C. Wyman, B. Dale, R. Elander, Y. Y. Lee, M. Holtzapple, M. Ladisch, Biores. Technol., 2005, 96, 673-686.

34 M. Zeng, E. Ximenes, M. R. Ladisch, N. S. Mosier, W. Vermerris, C. P. Huang, D. M. Sherman, Biotechnol. Bioeng., 2012, 109, 390-397.

35 R. A. Dixon, Nature, 2013, 493, 36-37.

36 T. Jeoh, C. I. Ishizawa, M. F. Davis, M. E. Himmel, W. S. Adney, D. K. Johnson, 415 Biotechnol. Bioeng., 2007, 98, 112-122.

37 H. Li, Y. Pu, R. Kumar, A. J. Ragauskas, C. E. Wyman, Biotechnol. Bioeng., 2014, 111, 485- 
43238 Z. Forsberg, G. Vaaje-Kolstad, B. Westereng, A. C. Bunaes, Y. Stenstrom, A. MacKenzie, 433 M. Sorlie, S. J. Horn, V. G. H. Eijsink, Protein Sci., 2011, 20, 1479-1483.

434

43539 K. Woermeyer, T. Ingram, B. Saake, G. Brunner, I. Smirnova, Biores. Technol., 2011, 102, $436 \quad 4157-4164$.

437 


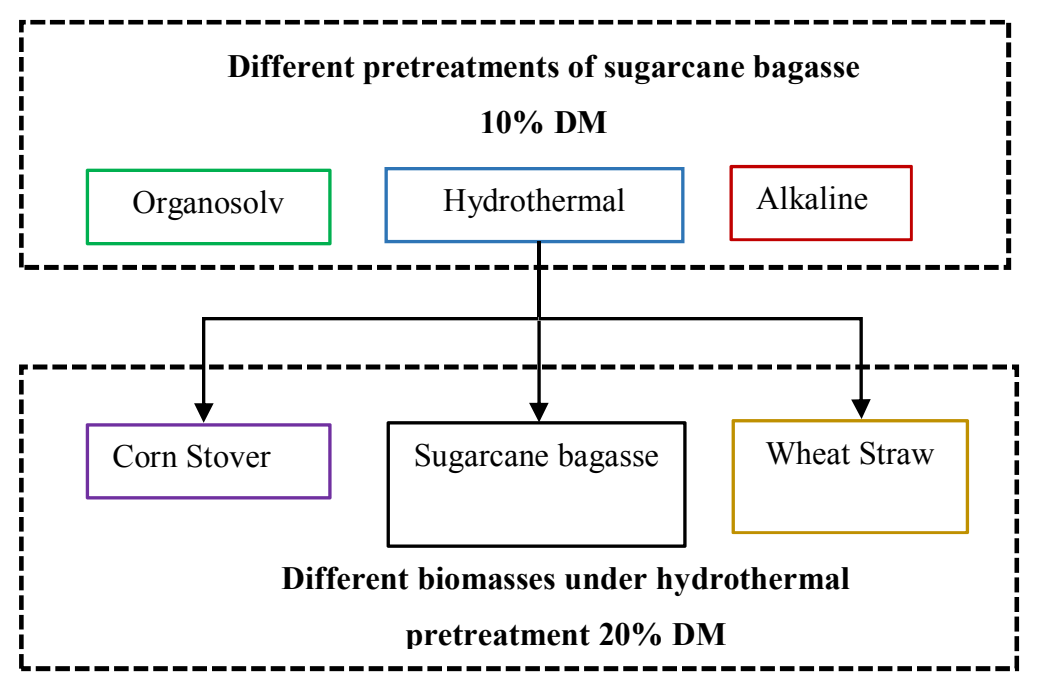

Figure 1 Methodology flow sheet: first raw sugarcane bagasse pretreated with various methods at $10 \%$ dry matter; second raw hydrothermal pretreatment applied at various biomasses at $20 \%$ dry matter. 


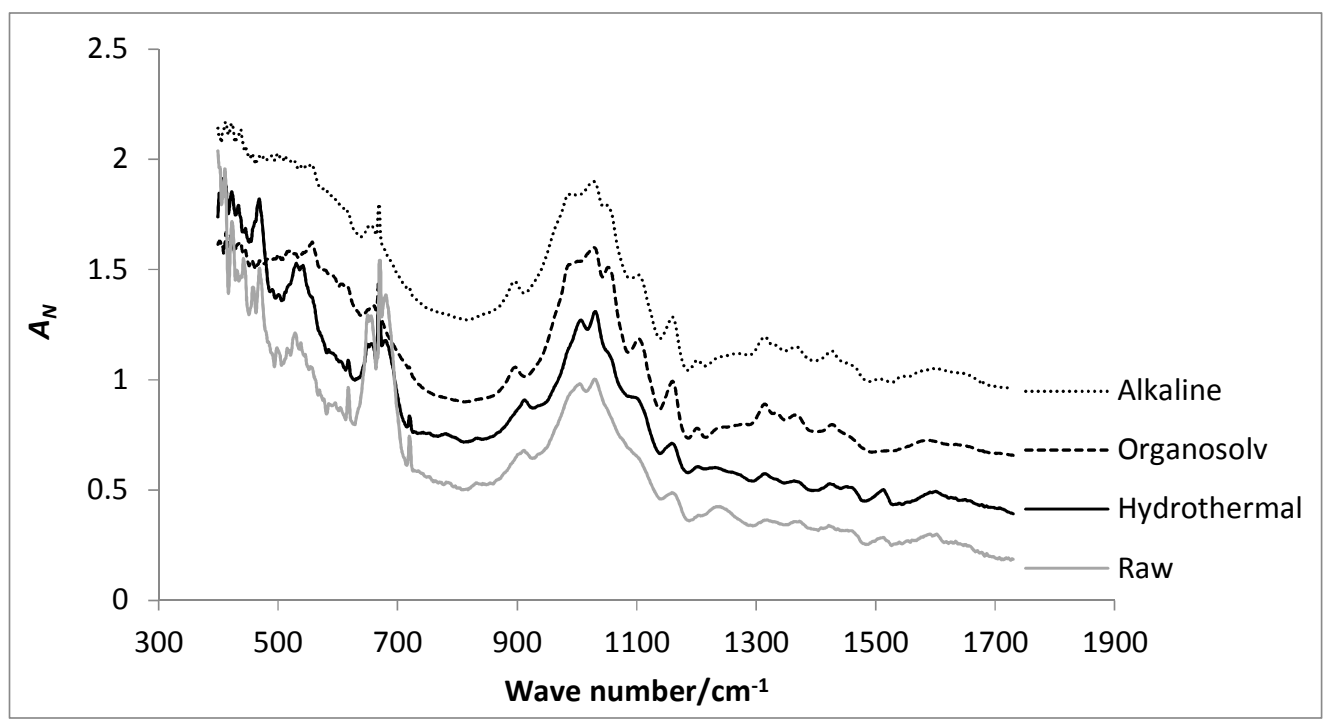

Figure 2. FT-IR spectra of raw sugar cane bagasse (raw) and after three different pretreatment technology: region between 950 and $1100 \mathrm{~cm}^{-1}$ is typically associated with cellulosic component of the material. 
464
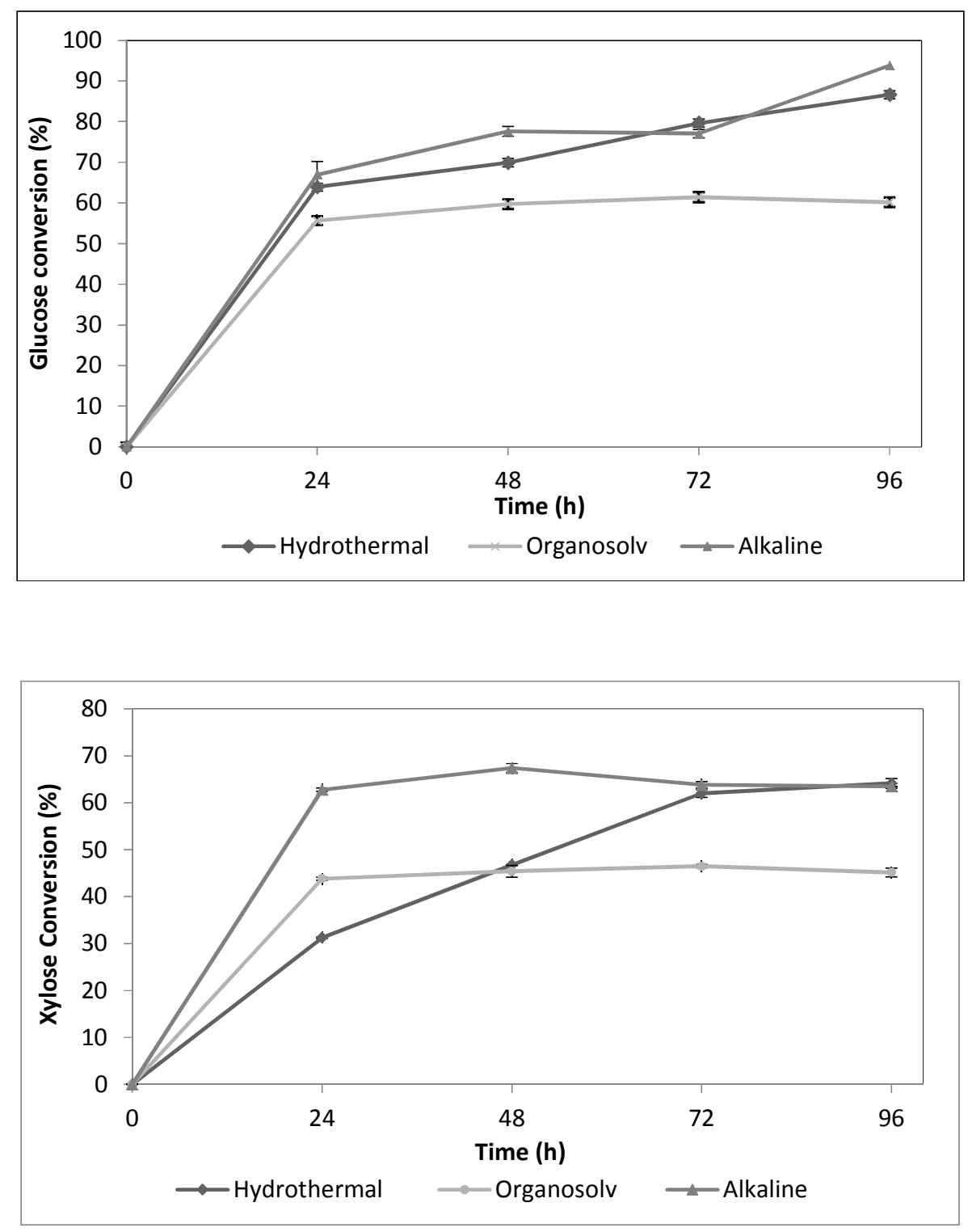

Figure 3. Enzymatic hydrolysis of sugarcane bagasse pretreated with different technologies: hydrothermal (rhombus), alkaline (triangle) and organosolv (circle). Experimental conditions: Cellic Ctec2 was used for the enzymatic hydrolysis with a loading of $10 \mathrm{FPU} / \mathrm{g}_{\text {dry cellulose }}, 96$ hours at $48^{\circ} \mathrm{C}, 15 \%(\mathrm{w} / \mathrm{w})$ dry matter load. The conversion is given as percentage based on the theoretical maximum glucose (upper plot) and xylose (bottom plot) yields from the pretreated materials. 


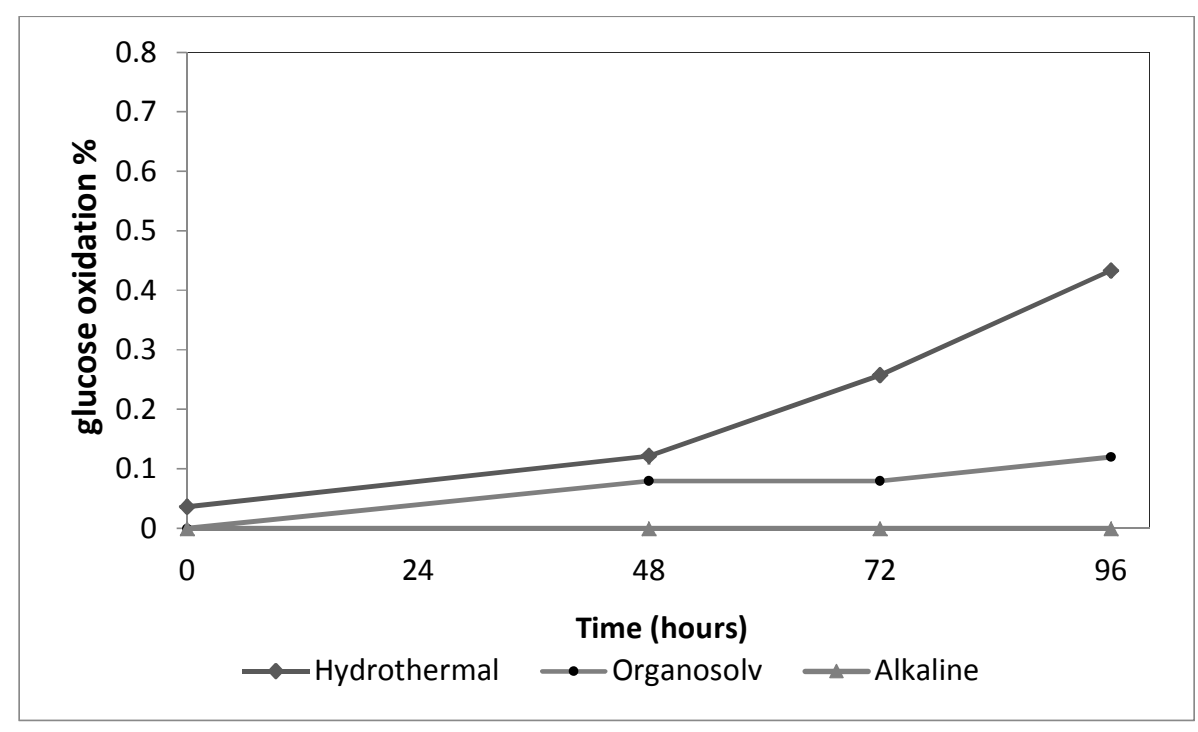

Figure 4. Glucose oxidation during the enzymatic hydrolysis of sugarcane bagasse pretreated with three different technologies: hydrothermal (rhombus), alkaline (triangle) and organosolv (circle). The glucose oxidation is calculated as percentage of amount of gluconic acid over amount of glucose hydrolyzed from cellulose. 
486

487

488
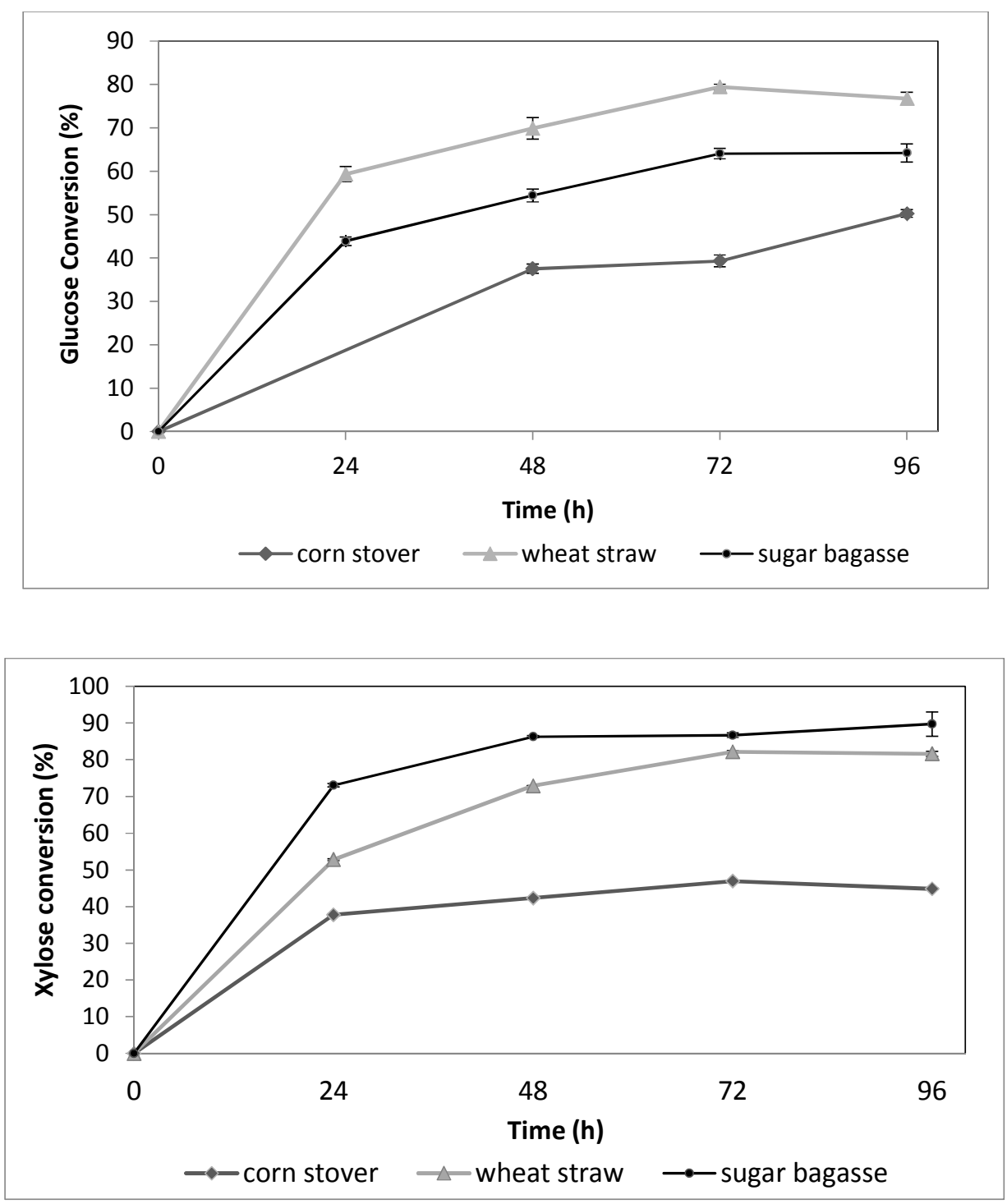

Figure 5. Hydrolysis of the hydrothermally pretreated biomasses: corn stover (rhombus), wheat straw (triangle) and sugarcane bagasse (circle). Experimental conditions: Cellic Ctec2 was used for the enzymatic hydrolysis with a loading of $10 \mathrm{FPU} / \mathrm{g}_{\text {dry cellulose, }}, 96$ hours at $48^{\circ} \mathrm{C}, 15 \%(\mathrm{w} / \mathrm{w})$ dry matter load. The conversion is given as percentage based on the theoretical maximum glucose (upper plot) and xylose (bottom plot) yields from the pretreated materials. 
498

499

500

501

502

503

504

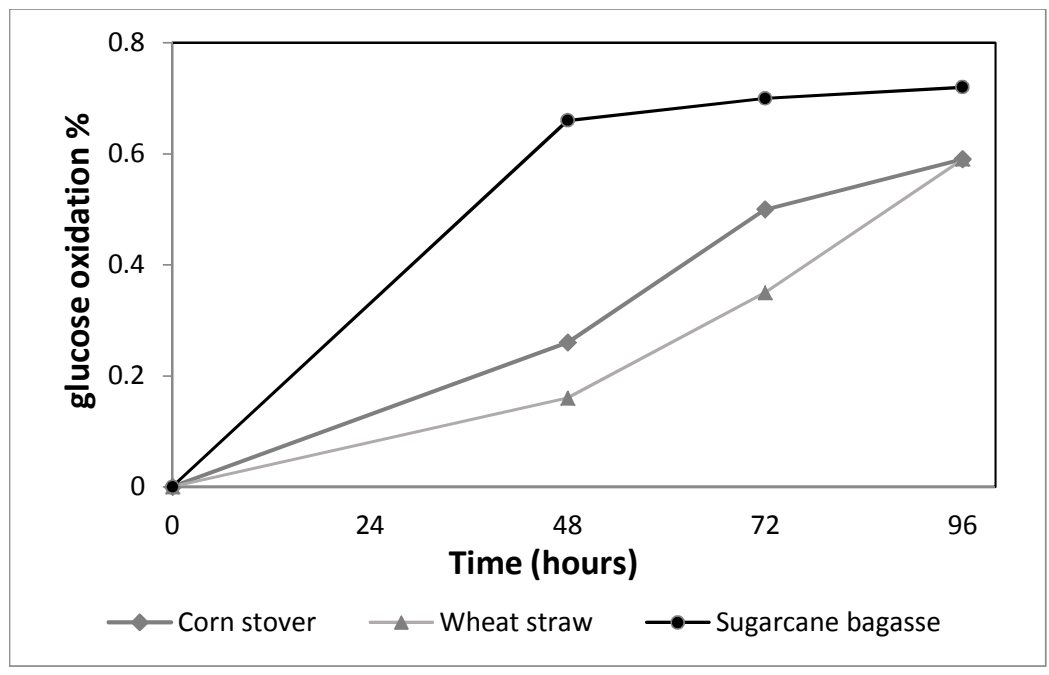

Figure 6. Glucose oxidation during the enzymatic hydrolysis with CellicCtec 2 at $15 \% \mathrm{DM}$ of hydrothermalpretreated materials: corn stover (rhombus), wheat straw (triangle) and sugarcane bagasse (circle), same conditions as described in figure 4. 
506 Compositional analysis of Bagasse native biomass, and after hydrothermal, organosolv and alkaline

507 pretreatment at $10 \%$ of solids loading.

\begin{tabular}{cccccccc}
\hline & Glucan & Xylan & Mannan & Arabinan & Galactan & $\begin{array}{c}\text { Klason } \\
\text { Lignin }\end{array}$ & Ashes \\
\hline Native & $42.9 \pm 2.2$ & $19.5 \pm 1.6$ & nd & $2.6 \pm 0.2$ & $0.5 \pm 0.1$ & $23.0 \pm 0.3$ & $3.0 \pm 0.6$ \\
Hydrothermal & $45.2 \pm 0.9$ & $2.4 \pm 0.1$ & nd & nd & nd & $38.2 \pm 0.4$ & $4.9 \pm 0.8$ \\
Organosolv & $66.1 \pm 2.3$ & $14.5 \pm 0.1$ & $0.3 \pm 0.1$ & $0.4 \pm 0.1$ & nd & $9.6 \pm 1.0$ & $3.2 \pm 0.8$ \\
Alkaline & $72.2 \pm 3.1$ & $10.2 \pm 1.7$ & nd & $0.3 \pm 0.1$ & nd & $7.8 \pm 0.4$ & $4.3 \pm 0.6$ \\
\hline
\end{tabular}

Table

514 Compositional analysis of wheat straw, corn stover and bagasse of native biomass and after

515 hydrothermal pretreatment at $20 \%$ solids loading.

516

\section{Lignocellulosic fraction in \% of dry matter}

Glucan Xylan Mannan Arabinan Galactan $\begin{gathered}\text { Klason } \\ \text { Lignin }\end{gathered}$ Ashes

\begin{tabular}{|c|c|c|c|c|c|c|c|}
\hline \multirow{2}{*}{$\begin{array}{c}\text { Wheat Straw } \\
\text { Native }\end{array}$} & \multirow[b]{2}{*}{$46.0 \pm 2.2$} & \multirow[b]{2}{*}{$21.6 \pm 1.8$} & \multirow[b]{2}{*}{$1.5 \pm 0.2$} & \multirow[b]{2}{*}{$2.9 \pm 0.2$} & \multirow[b]{2}{*}{$1.2 \pm 0.2$} & \multirow[b]{2}{*}{$20.6 \pm 1.0$} & \multirow[b]{2}{*}{$2.3 \pm 0.3$} \\
\hline & & & & & & & \\
\hline $\begin{array}{c}\text { Hydrothermal } \\
\text { pretreat. }\end{array}$ & $54.7 \pm 1.6$ & $5.1 \pm 0.3$ & nd & nd & nd & $34.1 \pm 0.9$ & $3.3 \pm 0.6$ \\
\hline \multicolumn{8}{|l|}{ Corn Stover } \\
\hline \multirow{2}{*}{$\begin{array}{c}\text { Native } \\
\text { Hydrothermal } \\
\text { pretreat. }\end{array}$} & $45.9 \pm 0.9$ & $18.0 \pm 1.0$ & $1.7 \pm 0.3$ & $2.7 \pm 0.1$ & $1.0 \pm 0.1$ & $20.3 \pm 0.9$ & $2.6 \pm 0.2$ \\
\hline & $50.5 \pm 0.2$ & $2.2 \pm 0.1$ & nd & nd & nd & $35.1 \pm 0.3$ & $4.5 \pm 0.7$ \\
\hline \multicolumn{8}{|l|}{ Sugarcane bagasse } \\
\hline \multirow{2}{*}{$\begin{array}{c}\text { Native } \\
\text { Hydrothermal } \\
\text { pretreat. }\end{array}$} & $42.9 \pm 2.2$ & $19.5 \pm 1.6$ & nd & $2.6 \pm 0.2$ & $0.5 \pm 0.1$ & $23.0 \pm 0.3$ & $3.0 \pm 0.6$ \\
\hline & $45.2 \pm 2.1$ & $4.1 \pm 0.1$ & nd & $1.6 \pm 0.5$ & nd & $39.2 \pm 0.6$ & $5.1 \pm 0.8$ \\
\hline
\end{tabular}

517

518

519 
521 Gluconic acid and cellulose conversion yield after 96 hours of enzymatic hydrolysis compared to

522 lignin content of the residual fraction after each pretreatment.

523

\begin{tabular}{|c|c|c|c|}
\hline Solid fraction & $\begin{array}{l}\text { Gluconic acid } \\
\qquad(\mathrm{g} / \mathrm{kg})\end{array}$ & $\begin{array}{c}\text { Cellulose } \\
\text { conversion yield } \\
(\%)\end{array}$ & $\begin{array}{c}\text { Klason } \\
\text { Lignin ( } \% \\
\text { DM) } \\
\end{array}$ \\
\hline Bagasse & & & \\
\hline Hydrothermal & 0.38 & 86.6 & 38.2 \\
\hline Organosolv & 0.07 & 60.2 & 9.6 \\
\hline Alkali & nd & 93.8 & 7.8 \\
\hline \multicolumn{4}{|l|}{ Hydrothermal } \\
\hline Corn stover & 0.25 & 50.2 & 35.1 \\
\hline Wheat straw & 0.40 & 76.8 & 34.1 \\
\hline Bagasse & 0.46 & 64.2 & 39.2 \\
\hline
\end{tabular}

524 